\title{
Case report: effect of blood glucose/AIc on periodontal/alveolar bone health
}

\begin{abstract}
Diabetes and periodontal health relation is well established in literature. This case report shows reversal of bone loss on control of blood glucose and A1c level. Further study in this area suggested. Probably area with organic matrix intact got recalcified.

Keywords: diabetics, blood glucose, A1c, bone resorption, reversal of bone resorption
\end{abstract}

Volume 9 Issue 2 - 2018

\section{Samar Tanous,' Bharat C Joshi ${ }^{2}$}

Instructor, Cardiology and comprehensive care, Private Practice, General Dentistry, USA

Associate Professor, Prosthodontics, New York University,

Private Practice prosthodontics, USA

\begin{abstract}
Correspondence: Bharat C Joshi Prosthodontist, Associate Professor, Prosthodontics, New York, University Private Practice prosthodontics, Hastings-on-Hudson, New York, USA, Email dentalimplantprosthesis@gmail.com
\end{abstract}

Received: October 04, 2017 | Published: April 18, 2018

\section{Case presentation}

Effect of diabetes on periodontal health is well established in publications. This case report describes condition of periodontium health prier to, at time of Diagnosis of Diabetes type II, and follow up changes up on control of glucose andA1c level, in one, three and five years on $\mathrm{x}$-rays and clinical findings/symptoms. It was surprising, at list for me, to notice recalcification of bone after control of blood glucose and A1c level. Patient BJ reported to me for checkup in late 15. Patient has positive history of Diabetes type II, since 3 years. Was diagnosed as a result of pre surgical checkup. Patient gives history of blood glucose of $310 \mathrm{mg} / 100 \mathrm{cc}$, and $11 \mathrm{Alc}$. Is on Metformin $1500 \mathrm{mg} /$ day and glucose is in normal limits and A1c 5.5. Also mention that had mobility and pain on function on left side, and a little on right side first molars, lower. Currently there is no pain and minimal mobility in both lower first molars. Confirming of history with x-rays patient have, had decent bone level in 1997 and 2011 x-rays (Figure 1) and show bone loss including furcation area in \#19 area in 2012 (one year) 2013 (two years) x-rays (Figure 2) and improvement in 2015 (Three years after diagnosis)and 2017 (five years after diagnosis) (Figure 3) films.

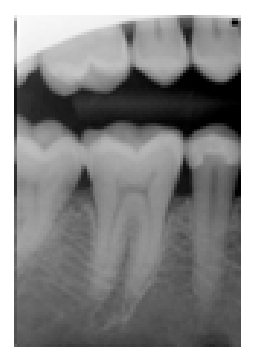

$12 / 6 / 1997$

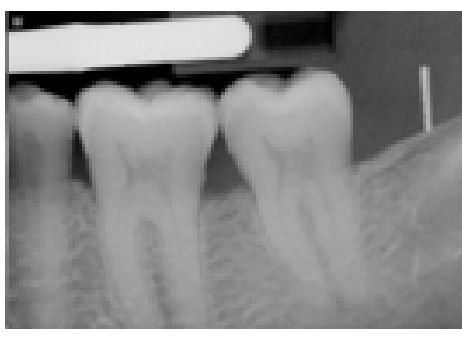

$07 / 23 / 2011$
Figure I

Early intervention in Diabetic patients, bone loss without destruction of organic matrix probably can reverse with glucose level and A1c level bringing down to normal level. This patient maintains glucose level between 90 and 140, indicative on A1c level. We should look in to early periodontal disease patient to rule out Diabetes as contributing factor, and if detected high glucose blood level/A1c, patient should be made aware of possibility of reversing condition with benefit of healthier periodontium, and extractions should be postponing whenever possible, till blood glucose/A1c is under control for 6 months. Further research work in this area is highly recommended.

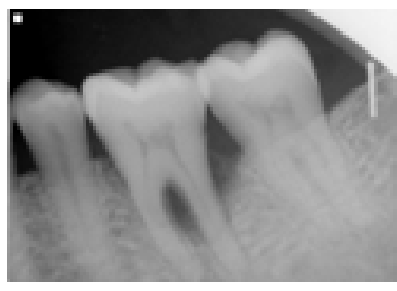

$11 / 02 / 2012$

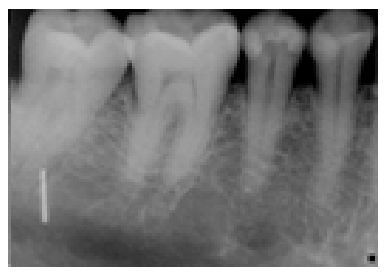

$03 / 09 / 2013$

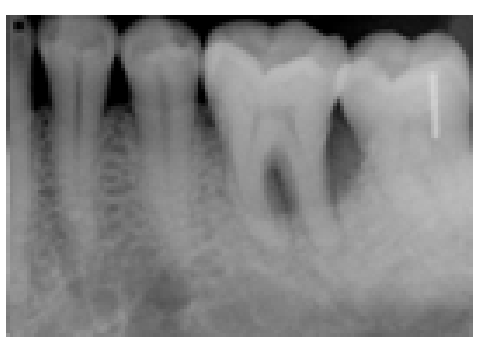

Figure 2

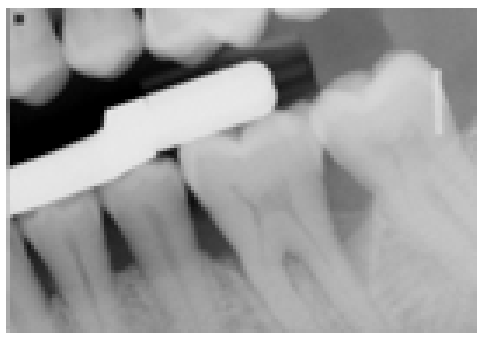




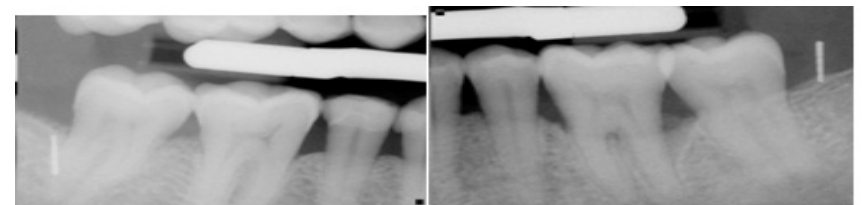

$09 / 02 / 2017$

\section{Figure 3}

Note: I am this patient and have no symptoms or any pain on chewing, I like to eat nuts and have no problem.

\section{Acknowledgement}

None.

\section{Conflict of interest}

None. 